\title{
Sizing Stand-Alone Photovoltaic Systems
}

\author{
A. Balouktsis, ${ }^{1}$ T. D. Karapantsios, ${ }^{2}$ A. Antoniadis, ${ }^{3}$ D. Paschaloudis, ${ }^{1}$ A. Bezergiannidou, ${ }^{1}$ and N. Bilalis ${ }^{4}$ \\ ${ }^{1}$ Department of Informatics \& Communications, Technological Educational Institution of Serres, Terma Magnesias, \\ P.O. Box 62124, Serres, Greece \\ ${ }^{2}$ Department of Chemistry, Aristotle University of Thessaloniki, University Box 116, 54124 Thessaloniki, Greece \\ ${ }^{3}$ Department of Natural Resources \& Environment, Technological Educational Institution of Crete, Romanou 3, 731 33 Chania, Greece \\ ${ }^{4}$ Department of Production Engineering \& Management, Technical University of Crete, University Campus, 73100 Chania, Greece
}

Received 25 February 2005; Revised 28 August 2005; Accepted 5 September 2005

\begin{abstract}
A method of sizing stand-alone photovoltaic systems regarding the reliability to satisfy the load demand, economy of components, and discharge depth exploited by the batteries is presented in this work. Solar radiation data simulated by an appropriate stochastic time series model, and not actual measurements, are used in the sizing procedure. This offers two distinct advantages: (a) sizing can be performed even for locations where no actual data exist, (b) the influence of the variation of the statistical parameters of solar radiation in sizing can be examined. The method has been applied and tested for several representative locations all over Greece for which monthly daily average values of solar radiation are given by ELOT (Hellenic Organization of Standardization).
\end{abstract}

Copyright (c) 2006 A. Balouktsis et al. This is an open access article distributed under the Creative Commons Attribution License, which permits unrestricted use, distribution, and reproduction in any medium, provided the original work is properly cited.

\section{INTRODUCTION}

An essential first step when designing a stand-alone photovoltaic (PV) system is to determine the total power of the PV system and the energy of the batteries in such a way that the system becomes capable of satisfying the load (demand) at a given reliability level and minimum cost. Sizing a PV system is, apparently, a quite complex issue because several stochastic parameters are involved having a significant contribution, e.g., meteorological data, variation of demand on daily and seasonal bases, and economical considerations.

So far, several methods have been proposed in the literature for sizing stand-alone photovoltaic systems [1-5]. These methods either rely on tabulated seasonal-monthly average values of solar radiation and employ simplified calculations, or rely on daily/hourly measured values of solar radiation and incorporate simulation techniques. The simplified methods are generally not satisfactory; especially for cases where increased reliability is required as regards the response to the electric consumptions. On the other hand, the simulation methods require detailed information on a daily or hourly basis for prolonged periods of time (above 10 years), which is often not available. An alternative and perhaps more efficient approach when using simulation methods is to employ stochastic models for generating solar radiation data which retain all the essential stochastic features (radiation distributions, correlations, etc.) of the actual data. Such stochastic models have been sporadically communicated in the past [6-9].

The present study is concerned with sizing stand-alone photovoltaic systems for different locations in Greece. To produce hourly solar radiation data, the stochastic model of [9] is employed (with some refinements), for it involves the fewer and, virtually, the more salient statistical parameters of solar radiation (tabulated monthly average daily values and the respective standard deviations). If tabulated standard deviations values do not exist, they can still be estimated by the stochastic model of Bent et al. [10]. Certain key simplifications in the theoretical problem formulation in that study allowed the development of a realistic, yet sufficiently simple, model with broad applicability which can be used as a convenient diagnostic tool for investigating the sensitivity of the design of a stand-alone photovoltaic system to the variation of the aforementioned statistical parameters. Tabulated monthly average values of daily solar radiation data, needed as input to the simulation code, are taken by ELOT [11], whereas standard deviations are estimated from measured daily values of solar radiation for the Greek cities of Serres, Kavala, Athens, and Hania. This is done in the absence of original standard deviation data for most of the locations considered herein. However, to partly overcome this uncertainty, the possible effect of the standard deviation variation to the system design 


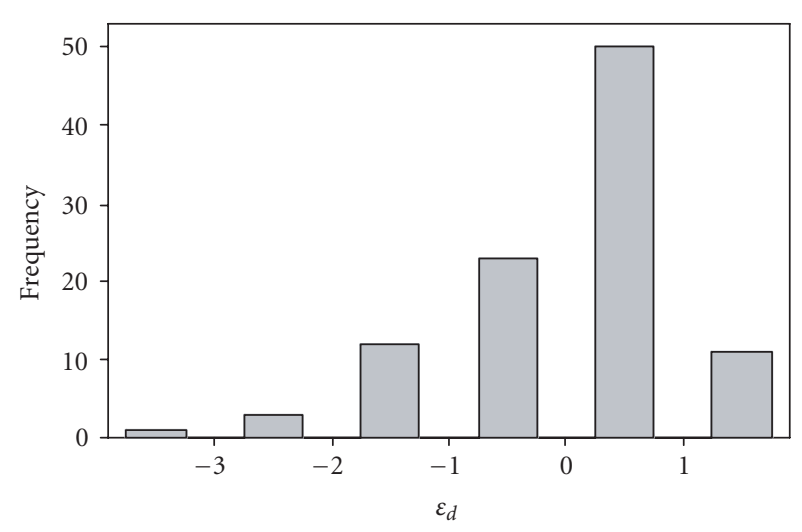

Figure 1: Histogram of $\varepsilon_{d}$ distribution.

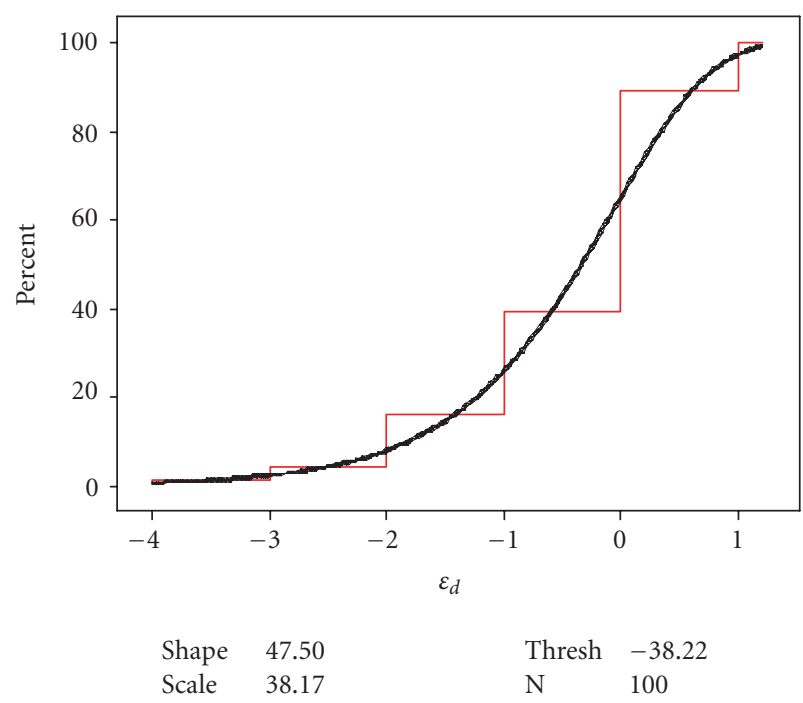

FIgURE 2: 3-parameter Weibull distribution approximation of original $\varepsilon_{d}$ distribution.

is thoroughly examined. In addition, it is investigated how the batteries' discharge depth affects the optimum design considering that it is directly associated with their durability.

It is of great importance to realize prior to PV sizing whether the system design is accurate enough when it is based on simulated data alone. In pursuing this goal, a comparison is made between designs based on actual measurements of solar radiation in Serres and simulated data computed from the average values of the actual measurements for a period of a year.

\section{STOCHASTIC MODEL OF SOLAR RADIATION}

If the daily clearness index is defined as

$$
K_{d}=\frac{G_{d}}{G_{o, d}}
$$

( $G_{d}$ is the daily solar radiation and $G_{o, d}$ the extraterrestrial solar radiation for the same day), then according to [9] the clearness index $K_{d}$ can be described by a time series:

$$
K_{d}=\mu_{d}+\sigma_{d} \cdot \varepsilon_{d}
$$

where $\mu_{d}=E\left(K_{d}\right)$ is the expected $K_{d}$ value at day $d, \sigma_{d}=$ $\sqrt{E\left[\left(K_{d}-\mu_{d}\right)^{2}\right]}$ is the standard deviation of $K_{d}$ at day $d$, and $\varepsilon_{d}$ is a static (error) time series with $E\left(\varepsilon_{d}\right)=0, E\left(\varepsilon_{d}^{2}\right)=1$ with a correlation coefficient among its successive elements of $\rho=0.23$ and a distribution as displayed in Figure 1.

The above distribution can be approximated by a 3parameter Weibull distribution as it is shown in Figure 2. This is a refined approach with respect to what was used in [9].

The daily values of $\mu_{d}$ for the whole year are derived from tabulated average monthly values (12 values per year) by simple linear interpolation. The same applies also for the daily $\sigma_{d}$.

In cases that there are no available $\sigma_{d}$ data, these values can be obtained from Figure 3 which was deduced from 


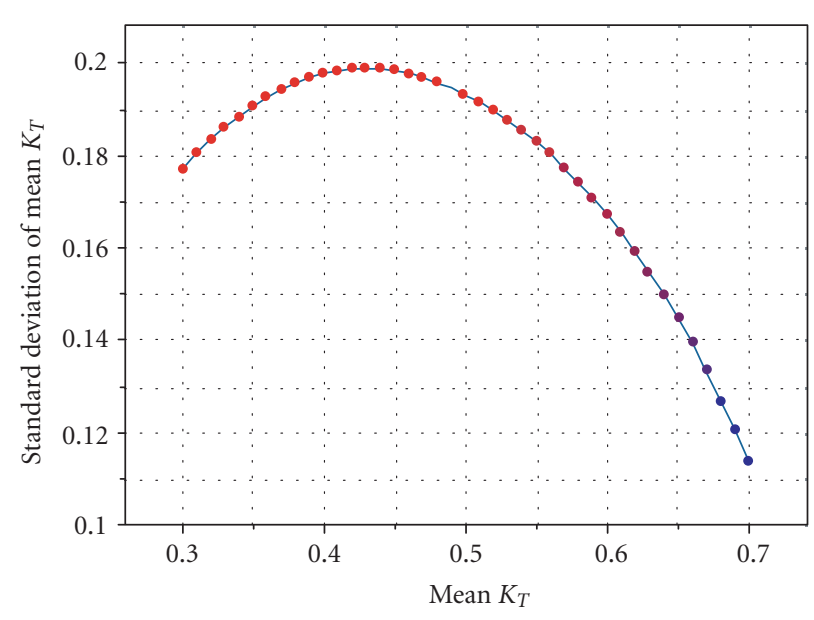

FIGURE 3: Estimated standard deviations, $\sigma_{d}$, for different mean clearness indexes.

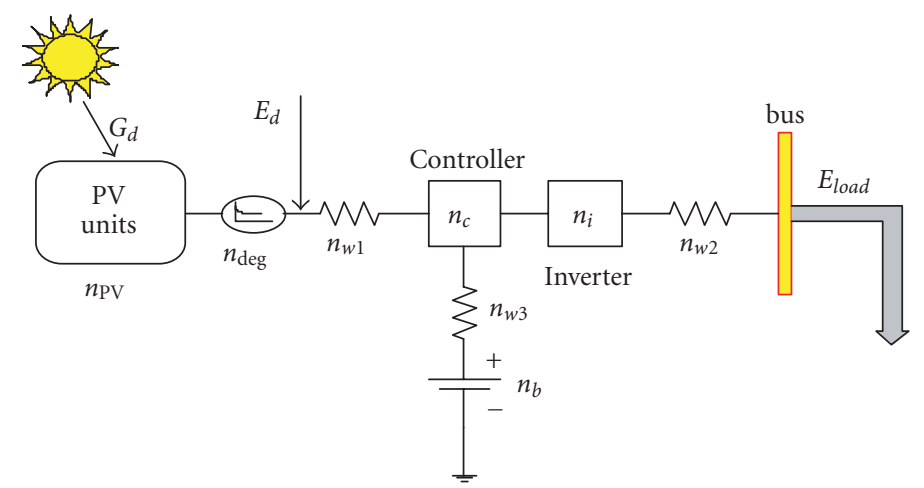

FIGURE 4: Schematic representation of a stand-alone PV system. $n_{\mathrm{PV}}$ : efficient factor of PV units, $n_{w 1}$ : line efficient factor between PVconverter, $n_{w 2}$ : line efficient factor between inverter-load, $n_{i}$ : efficient factor of inverter, $n_{c}$ : efficient factor of converter, $n_{w 3}$ : line efficient factor between converter-batteries, $n_{b}$ : efficient factor of batteries, $n_{\mathrm{deg}}$ : degradation coefficient of PV units.

the clearness index distributions in [10]. The corresponding standard deviations are estimated from the relation:

$$
\sigma_{d}=\sqrt{\int_{K_{d, \min }}^{K_{d, \max }}\left(K_{d}-\mu_{d}\right)^{2} p d f_{\mu d}\left(K_{d}\right) d K_{d}}
$$

\section{SIMULATION METHODOLOGY}

A typical stand-alone photovoltaic system consists of a number of PV units connected in series and in parallel, batteries, a converter or controller for supervising the charging and discharging of the batteries, and, finally, one or more inverters connected in parallel, for the case that an alternating current balance is included in the system. Figure 4 illustrates better the energy approach that is incorporated in the sizing procedure where, in addition to the individual units, the corresponding efficiency coefficients are also depicted.

In the simulation, the energy balance between production and demand is inspected during the daytime in two stages: one from sunrise to sunset and another for the rest of the day. The most important inspection steps are as follows.

(a) The daily solar irradiation is converted from the horizontal, $G_{h}$, to the inclined plane of the photovoltaic units, $G_{t}$. Total irradiance on the PV array plane is calculated using an isotropic model for both the diffuse irradiation and the ground reflected irradiation. Calculations by this model take into account the location latitude. Details on the above can be found in classic solar engineering books, e.g., [12];

(b) The energy of the photovoltaic, $E_{d}$, is estimated for the period of a day by the relation

$$
E_{d}=n_{\mathrm{deg}} n_{\mathrm{PV}} G_{t}
$$

Then, the energy at the level of the alternating current balance (bus point) is calculated from the formula

$$
E_{d, \mathrm{load}}=E_{d} n_{w 1} n_{w 2} n_{i}
$$

Next, this value is compared to the daylight energy demand $E_{\text {light,load }}$ where two different cases are considered:

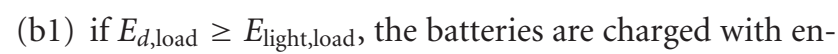
ergy equal to

$$
\left(E_{d, \text { load }}-E_{\text {light,load }}\right) \frac{n_{w 3} n_{c} n_{b}}{n_{w 2} n_{i}}
$$

with the simulation checking at the same time for the batteries not to be overcharged, 


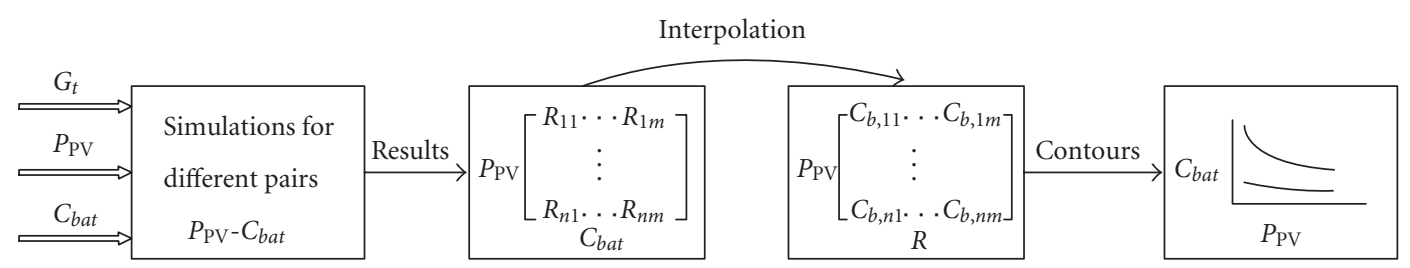

FIgURE 5: Block diagram of simulation methodology to produce $C_{\text {bat }}$ versus $P_{\mathrm{PV}}$ curves.

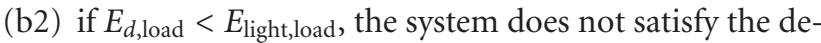
mand for a period of time equal to

$$
\left(E_{\text {light,load }}-E_{d, \text { load }}\right) \frac{\tau_{d}}{E_{\text {light,load }}},
$$

where $\tau_{d}$ is the duration of the daylight which has a different value for every day of the year;

(c) For the night hours, the energy demand $E_{\text {night,load }}$ is satisfied exclusively by the batteries and, therefore, they are discharged by an amount of energy equal to

$$
\frac{E_{\text {night,load }}}{n_{w 1} n_{w 3} n_{i}}
$$

where $E_{\text {load }}=E_{\text {light,load }}+E_{\text {night,load }}$.

The simulation checks at the same time for the batteries not to be discharged below the minimum depletion level which is determined by the discharge depth. For the case that the balance of the energy at bus point requires discharge of the batteries below their minimum level, then the system is considered as not satisfying the demand for a period of time proportional to the energy not covered.

Following the above steps, the behavior of the system is examined separately for every different location and for an extended period of 10 years. Specifically, for every pair of PV power-batteries energy, the reliability index of the system is calculated, defined as the ratio of the hours satisfying the demand over the total hours of simulation:

$$
R=\frac{\text { hours satisfying the load }}{\text { total hours of simulation }} .
$$

Running the simulation code for an individual pair of PV power-batteries energy, a single value for the reliability index is calculated. For a series of different pairs, a table is constructed of reliability indexes versus pairs of PV powerbatteries energy. The resolution of this table can be made as fine as desired in order to attain the required accuracy. Any PV power value is then interpolated among the elements of this table to obtain the corresponding value of the batteries, capacity for the different reliability levels of the system specified by the user. In other words, points of the function $f\left(P_{\mathrm{PV}}, C\right)=R$ are evaluated. Subsequently, using nonlinear least squares numerical methods, the above functions are materialized into the general form:

$$
\frac{a_{1}(R)+b_{1}(R) \cdot\left(P_{\mathrm{PV}}\right)^{2}}{1+b_{2}(R) \cdot\left(P_{\mathrm{PV}}\right)^{2}}=C_{\mathrm{bat}},
$$

where $P_{\mathrm{PV}}$ is the peak PV power in $\mathrm{kWp}$ and $C_{\text {bat }}$ the capacity of batteries in kWh.

The whole procedure is presented in Figure 5.

\section{DESIGN CONSIDERATIONS: PARAMETRIC INVESTIGATION}

In the present study, the proposed stochastic time series model has been utilized to generate solar radiation data because original measurements are not available for most of the locations encountered in the calculations. The success of this effort relies largely on whether the theoretically generated data resemble sufficiently the lacking measurements or, in other words, whether their statistical parameters adequately approximate the respective parameters of the missing actual data. Therefore, a comparison is made first between the simulated solar radiation values and measured data for a period of a year. The measured time series data and those determined from the simulation are displayed in Figures $6 \mathrm{a}$ and $6 \mathrm{~b}$, respectively. Table 1 presents the corresponding average values and standard deviations.

As can be seen, the maximum error in the average value is less than $9 \%$. Contrasting the sizing results obtained using the actual and the simulated data for Serres, at two different reliability levels $(0.9,0.99)$, the following are observed: at reliability 0.9 the design is almost identical (deviation less than $1 \%$ ) and at reliability 0.99 the deviation is less than $8 \%$, the data from the simulation producing always higher sizing values.

Next, the possible effect of the variation of standard deviation $(\sigma)$ of the radiation on the optimum design of the system is investigated. Figure 7 demonstrates the solar radiation time series produced by simulation with $0.2 \sigma, \sigma$, and $2 \sigma$ standard deviation for the city of Athens.

The mean percentage difference between the cases of $0.2 \sigma$ and $\sigma$ is: (a) for the economical components $-30 \%$, (b) for the capacity of the batteries $-50 \%$, (c) for the power of the PV $-15 \%$. When comparing the cases of $2 \sigma$ and $\sigma$ the respective values are: (a) for the economical components $16 \%$, (b) for the capacity of the batteries $50 \%$, (c) for the power of the PV $1 \%$.

Finally, the effect of the discharge depth of the batteries is examined as regards the design procedure. For this purpose, some necessary information from the literature [14] is utilized as reproduced in Table 2 . 


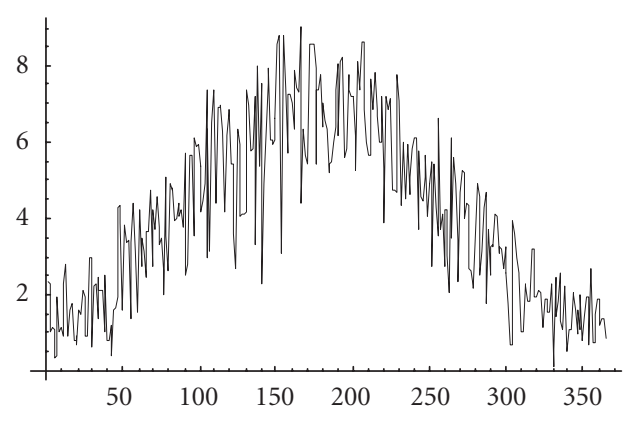

(a)

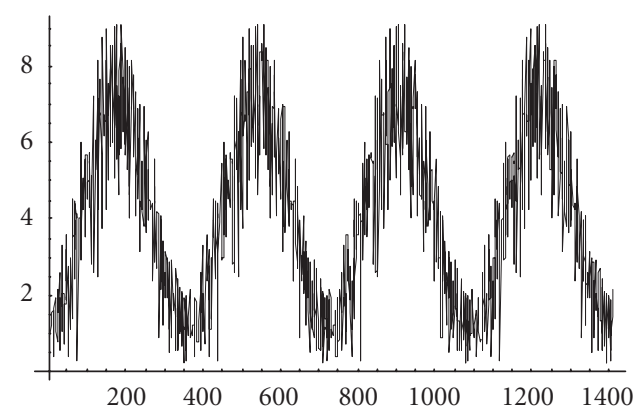

(b)

FIGURE 6: (a) Solar radiation data (kWh) measured in Serres (Greece) for one year, (b) solar radiation values simulated for Serres (Greece) for a period of 4 years.

TABLE 1: Comparison between actual and simulated monthly average solar radiation data for Serres (Greece).

\begin{tabular}{|c|c|c|c|c|c|c|c|c|c|c|c|c|}
\hline & Jan & Feb & Mar & Apr & May & Jun & Jul & Aug & Sep & Oct & Nov & Dec \\
\hline $\begin{array}{l}G_{d}, \text { actual, } \\
\text { kWh }\end{array}$ & 1.25 & 1.95 & 2.8 & 5.02 & 6.33 & 7.14 & 6.12 & 5.82 & 4.6 & 3.63 & 2.05 & 1.03 \\
\hline $\begin{array}{l}G_{d}, \text { simul, } \\
\text { kWh }\end{array}$ & 1.21 & 1.8 & 2.78 & 4.6 & 5.92 & 6.6 & 5.91 & 5.5 & 4.42 & 3.32 & 1.9 & 0.99 \\
\hline $\begin{array}{l}\text { Rel. error } \\
\%\end{array}$ & 3.2 & 7.7 & 0.7 & 8.4 & 6.5 & 7.6 & 3.4 & 5.5 & 3.9 & 8.5 & 7.3 & 3.9 \\
\hline
\end{tabular}

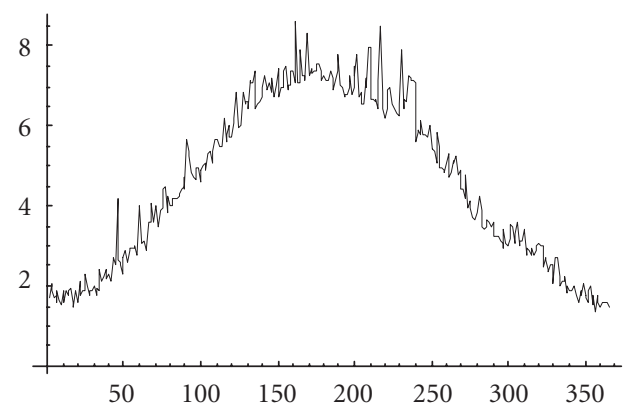

(a)

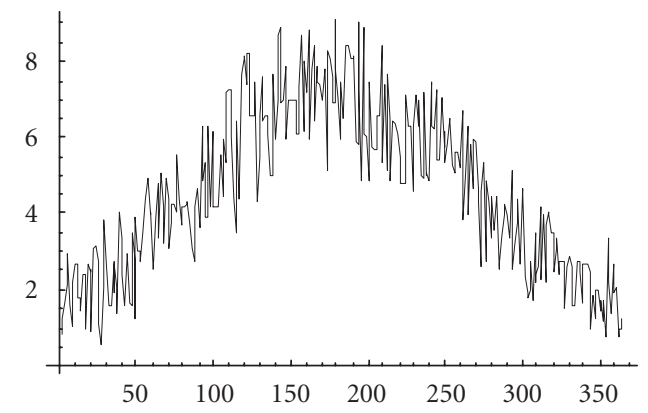

(b)

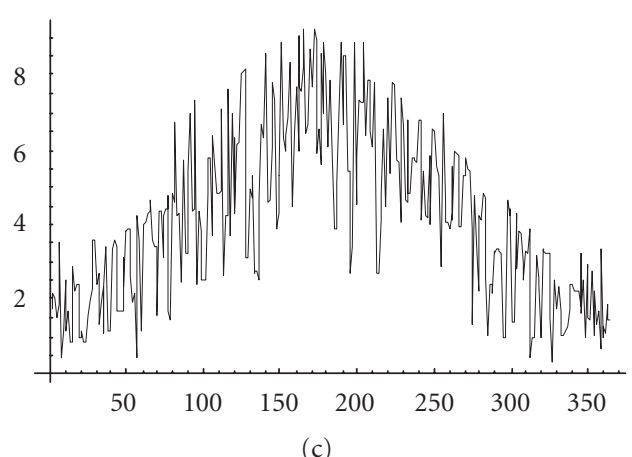

Figure 7: Yearly solar radiation (kWh) for (a) $0.2 \sigma$, (b) $\sigma$, and (c) $2 \sigma$ standard deviation for the city of Athens. 


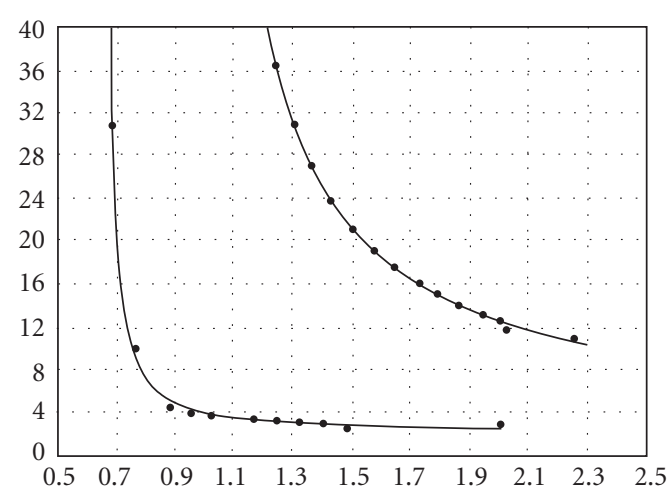

(a)

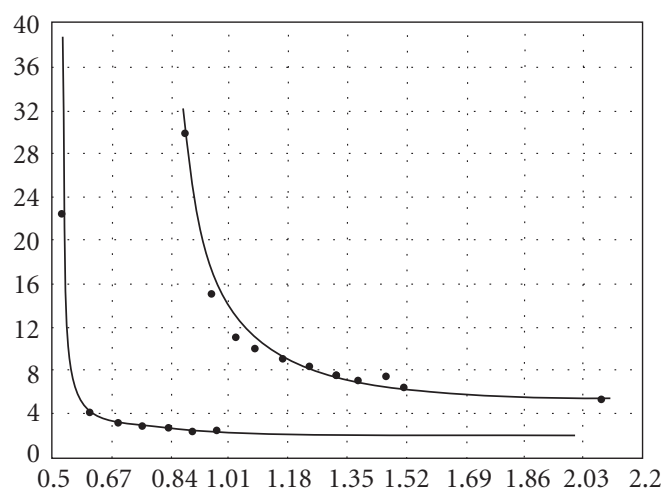

(b)

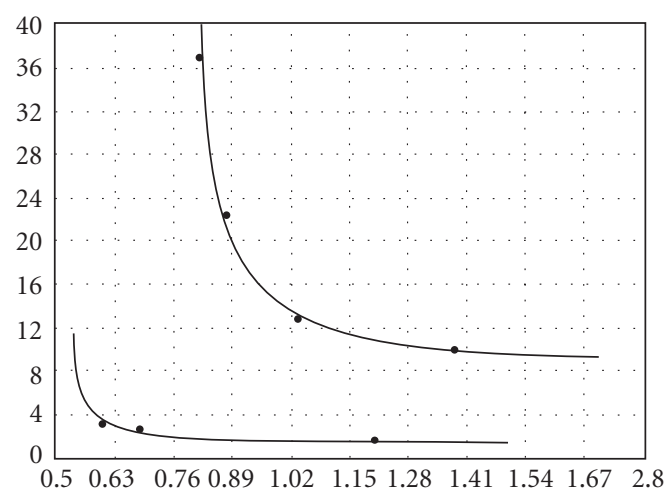

(c)

FIGURE 8: PV power-batteries energy curves at two different reliability levels $(0.9,0.99)$ for (a) Serres, (b) Athens, and (c) Hania.

TABLe 2: Battery life cycle (years) versus discharge depth (\%) for two different battery types.

\begin{tabular}{lcc}
\hline Life cycle, years & \multicolumn{2}{c}{ Discharge depth, \% } \\
\hline & For battery & For battery \\
$24-48 \mathrm{~V}$ & $>120 \mathrm{~V}$ \\
1 & 50 & 40 \\
5 & 35 & 25 \\
10 & 20 & 15 \\
15 & 15 & 10 \\
\hline
\end{tabular}

The sizing examination is conducted for PV systems for some Greek cities for which measured solar radiation data could be found. In all cases, the most economical design (for a 30-year life cycle of the total PV system) is attained by using batteries with discharge depths $<=35$. This value is eventually selected for the calculations of the present study.

\section{RESULTS}

For the course of the present calculations, the daily electric demand is taken as $1 \mathrm{kWh}$, constant throughout the year. The tilt of the photovoltaic units is set at a value equal to the latitude of each examined location plus 20 degrees. For all
TABLE 3: Economical parameters [13].

\begin{tabular}{lcc}
\hline & PV & Battery \\
\hline Purchase cost & $12 \$ / \mathrm{Wp}$ & $120 \$ / \mathrm{kWh}$ \\
Maintance & $0 \$$ & $0 \$$ \\
\hline
\end{tabular}

economical considerations, costs are taken from Table 3 according to the work of Lasnier and Ang [13].

Furthermore, the PV cost recently announced by the American Department of Energy, $5 \$ / \mathrm{Wp}$, is also employed for the sake of comparison. The discharge depth is assumed to be constant at 35\% which results in a batteries' life cycle of 5 years.

Figure 8 displays PV batteries curves of equal reliability as well as optimum points for the Greek cities of Serres, Athens, and Hania.

The PV sizing method and the stochastic radiation time series model (both described above) combined with tabulated monthly radiation values were successfully applied for sizing stand-alone PV systems at different locations in Greece.

Table 4 summarizes (a) information as provided by ELOT [11] on the latitude and minimum monthly average daily solar radiation on the tilted plane $\bar{G}_{d, t}$, (b) battery 
Table 4: Sizing PV systems for different locations in Greece.

\begin{tabular}{|c|c|c|c|c|c|c|c|c|}
\hline \multirow[b]{2}{*}{ Location } & \multirow[b]{2}{*}{$\begin{array}{l}\text { Reliability } \\
\text { index }\end{array}$} & \multirow[b]{2}{*}{ Latitude } & \multirow[b]{2}{*}{$\begin{array}{c}\operatorname{Min} \bar{G}_{d, t} \\
(\mathrm{kWh})\end{array}$} & \multicolumn{2}{|c|}{$12 \$ / W p$} & \multicolumn{2}{|c|}{$5 \$ / W p$} & \multirow[b]{2}{*}{ Zones } \\
\hline & & & & $\begin{array}{c}C_{\text {bat }} \\
(\mathrm{kWh})\end{array}$ & $\begin{array}{c}\mathrm{PV}_{\text {power }} \\
(\mathrm{Wp})\end{array}$ & $\begin{array}{c}C_{\text {bat }} \\
(\mathrm{kWh})\end{array}$ & $\begin{array}{c}\mathrm{PV}_{\text {power }} \\
(\mathrm{Wp})\end{array}$ & \\
\hline & 0.9 & & & 5.6 & 803 & 4.7 & 887 & \multirow{6}{*}{ G } \\
\hline Serres & 0.99 & $41^{\circ} 07^{\prime}$ & 1.405 & 17.7 & 1601 & 14.7 & 1881 & \\
\hline \multirow{3}{*}{ Thessaloniki } & 0.9 & & & 4.4 & 754 & 3.63 & 824 & \\
\hline & 0.99 & $40^{\circ} 33^{\prime}$ & 2.331 & 16 & 1272 & 13.56 & 1496 & \\
\hline & 0.9 & & & 5.24 & 787 & 4.24 & 878 & \\
\hline Ioannina & 0.99 & $39^{\circ} 42^{\prime}$ & 2.015 & 16.34 & 1193 & 13.8 & 1424 & \\
\hline \multirow{3}{*}{ Lamia } & 0.9 & & & 3.89 & 675 & 3.21 & 738 & \multirow{4}{*}{$\mathrm{F}$} \\
\hline & 0.99 & $38^{\circ} 54^{\prime}$ & 2.535 & 9.35 & 983 & 7.74 & 1130 & \\
\hline & 0.9 & & & 5.54 & 790 & 4.46 & 890 & \\
\hline Corfu & 0.99 & $39^{\circ} 47^{\prime}$ & 2.378 & 15.56 & 1240 & 12.9 & 1490 & \\
\hline \multirow{3}{*}{ Aliartos } & 0.9 & & & 5.26 & 820 & 4.2 & 920 & \multirow{4}{*}{$\mathrm{E}$} \\
\hline & 0.99 & $38^{\circ} 23^{\prime}$ & 2.14 & 11.3 & 1150 & 9.15 & 1350 & \\
\hline & 0.9 & & & 5.3 & 780 & 4.25 & 880 & \\
\hline Limnos & 0.99 & $39^{\circ} 55^{\prime}$ & 1.768 & 9.17 & 1260 & 7.13 & 1450 & \\
\hline \multirow[b]{2}{*}{ Athens } & 0.9 & & & 4 & 665 & 3.2 & 743 & \multirow{6}{*}{$\mathrm{D}$} \\
\hline & 0.99 & $37^{\circ} 58^{\prime}$ & 2.304 & 9.4 & 1142 & 7.5 & 1324 & \\
\hline \multirow{3}{*}{ Araxos } & 0.9 & & & 5.08 & 660 & 4 & 760 & \\
\hline & 0.99 & $38^{\circ} 10^{\prime}$ & 2.73 & 8.5 & 1050 & 6.7 & 1220 & \\
\hline & 0.9 & & & 4.62 & 760 & 3.4 & 840 & \\
\hline Mytilini & 0.99 & $39^{\circ} 06^{\prime}$ & 2.24 & 11.46 & 1190 & 9.34 & 1410 & \\
\hline \multirow{3}{*}{ Kalamata } & 0.9 & \multirow{3}{*}{$37^{\circ} 04^{\prime}$} & \multirow{3}{*}{2.625} & 5 & 620 & 4.2 & 720 & \multirow{4}{*}{$\mathrm{C}$} \\
\hline & 0.99 & & & 9.5 & 1070 & 7.56 & 1250 & \\
\hline & 0.9 & & & 4.77 & 760 & 3.6 & 870 & \\
\hline Hios & 0.99 & $38^{\circ} 22^{\prime}$ & 2.27 & 10.65 & 1150 & 8.5 & 1350 & \\
\hline \multirow{3}{*}{ Hania } & 0.9 & & & 4.08 & 617 & 3.2 & 694 & \multirow{4}{*}{ B } \\
\hline & 0.99 & $35^{\circ} 30^{\prime}$ & 2.746 & 11.8 & 1114 & 9.7 & 1310 & \\
\hline & 0.9 & & & 5.5 & 600 & 4.4 & 700 & \\
\hline \multirow[t]{2}{*}{ Naxos } & 0.99 & $37^{\circ} 06^{\prime}$ & 2.29 & 9.8 & 1040 & 7.8 & 1230 & \\
\hline & 0.9 & & & 3.5 & 620 & 2.8 & 690 & \multirow{2}{*}{ A } \\
\hline Rhode & 0.99 & $36^{\circ} 23^{\prime}$ & 2.841 & 11.13 & 1030 & 8.98 & 1230 & \\
\hline
\end{tabular}

capacity $C_{\text {bat }},(\mathrm{kWh}),(\mathrm{c})$ the power of the PV given in $\mathrm{Wp}$. The above are provided for two PV costs, namely, $12 \$ / \mathrm{Wp}$ and $5 \$ / W p$. Classification of the various locations into different zones is performed according to the radiation levels as reported in [15].

\section{CONCLUSIONS}

The proposed method of sizing stand-alone photovoltaic systems in combination with an appropriate stochastic time series model for solar radiation offers two distinct advantages in sizing stand-alone PV systems: (a) sizing can be performed even for locations where no actual data exist, (b) the influence of the variation of the statistical parameters of solar radiation in sizing can be examined. The method has been successfully applied for several representative locations all over Greece. The capacities of the batteries incorporated in the system are seen. In addition, it is investigated how the batteries' discharge depth that the variance of solar radiation influences largely affects the optimum design considering that it is directly associated with their durability. The proposed method is the first step in an effort to produce a simplified generalized procedure for sizing stand-alone PV systems.

\section{ACKNOWLEDGMENT}

This work has been founded partially by the Greek Ministry of Education (program ARCHIMIDES I).

\section{REFERENCES}

[1] L. Barra, S. Catalanotti, F. Fontana, and F. Lavorante, "An analytical method to determine the optimal size of a photovoltaic plant," Solar Energy, vol. 33, no. 6, pp. 509-514, 1984.

[2] H. Saha, "Design of a photovoltaic electric power system for an indian village," Solar Energy, vol. 27, no. 2, pp. 103-107, 1981. 
[3] M. Buresch, Photovoltaic Energy Systems: Design and Installation, McGraw-Hill, New York, NY, USA, 1983.

[4] P. P. Groumpos and G. Papageorgiou, "An optimal sizing method for stand-alone photovoltaic power systems," Solar Energy, vol. 38, no. 5, pp. 341-351, 1987.

[5] E. Ofry and A. Braunstein, "The loss of power supply probability as a technique for designing stand-alone solar electrical (photovoltaic) systems," IEEE Transactions on Power Apparatus and Systems, vol. 102, pp. 1171-1175, 1983.

[6] B. J. Brinkworth, "Autocorrelation and stochastic modelling of insolation sequences," Solar Energy, vol. 19, no. 4, pp. 343-347, 1977.

[7] C. Mustacchi, V. Cena, and M. Rocchi, "Stochastic simulation of hourly global radiation sequences," Solar Energy, vol. 23, no. 1, pp. 47-51, 1979.

[8] L. Vergara-Dominguez, R. Garcia-Gomez, A. R. FigueirasVidal, J. R. Casar-Corredera, and F. J. Casajus-Quiros, "Automatic modelling and simulation of daily global solar radiation series," Solar Energy, vol. 35, no. 6, pp. 483-489, 1985.

[9] A. Balouktsis, D. Tsanakas, and G. Vachtsevanos, "Stochastic modeling of daily global solar radiation," International Journal of Solar Energy, vol. 7, no. 1, pp. 1-10, 1989.

[10] P. Bendt, M. Collares-Pereira, and A. Rabl, "The frequency distribution of daily insolation values," Solar Energy, vol. 27, no. 1, pp. 1-5, 1981.

[11] ELOT, Hellenic Organization of Standardization, No. 1291, 1991.

[12] J. A. Duffie and W. A. Beckman, Solar Engineering of Thermal Processes, John Wiley \& Sons, New York, NY, USA, 1991.

[13] F. Lasnier and T. G. Ang, Photovoltaic Engineering Handbook, Adam Hilger, Bristol, UK, 1990.

[14] M. S. Imamura, P. Helm, and W. Palz, Photovoltaic System Technology: A European Handbook, H.S. Stephens \& Associates, Bedford, UK, 1992.

[15] A. Hadj Arab, B. Ait Driss, R. Amimeur, and E. Lorenzo, "Photovoltaic systems sizing for Algeria," Solar Energy, vol. 54, no. 2, pp. 99-104, 1995. 


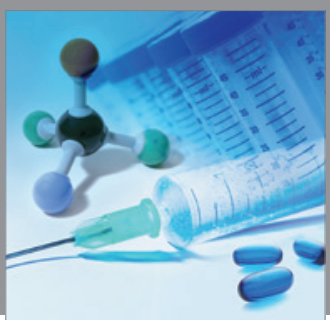

International Journal of

Medicinal Chemistry

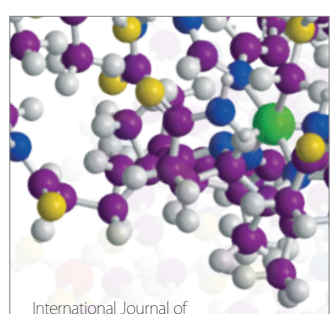

Carbohydrate Chemistry

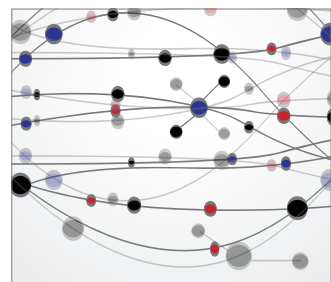

The Scientific World Journal
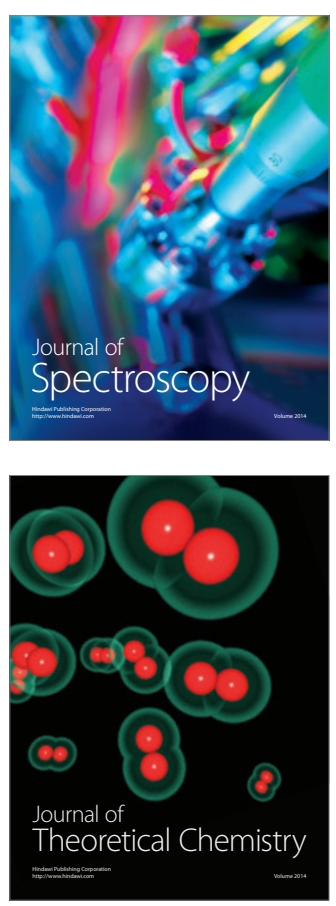
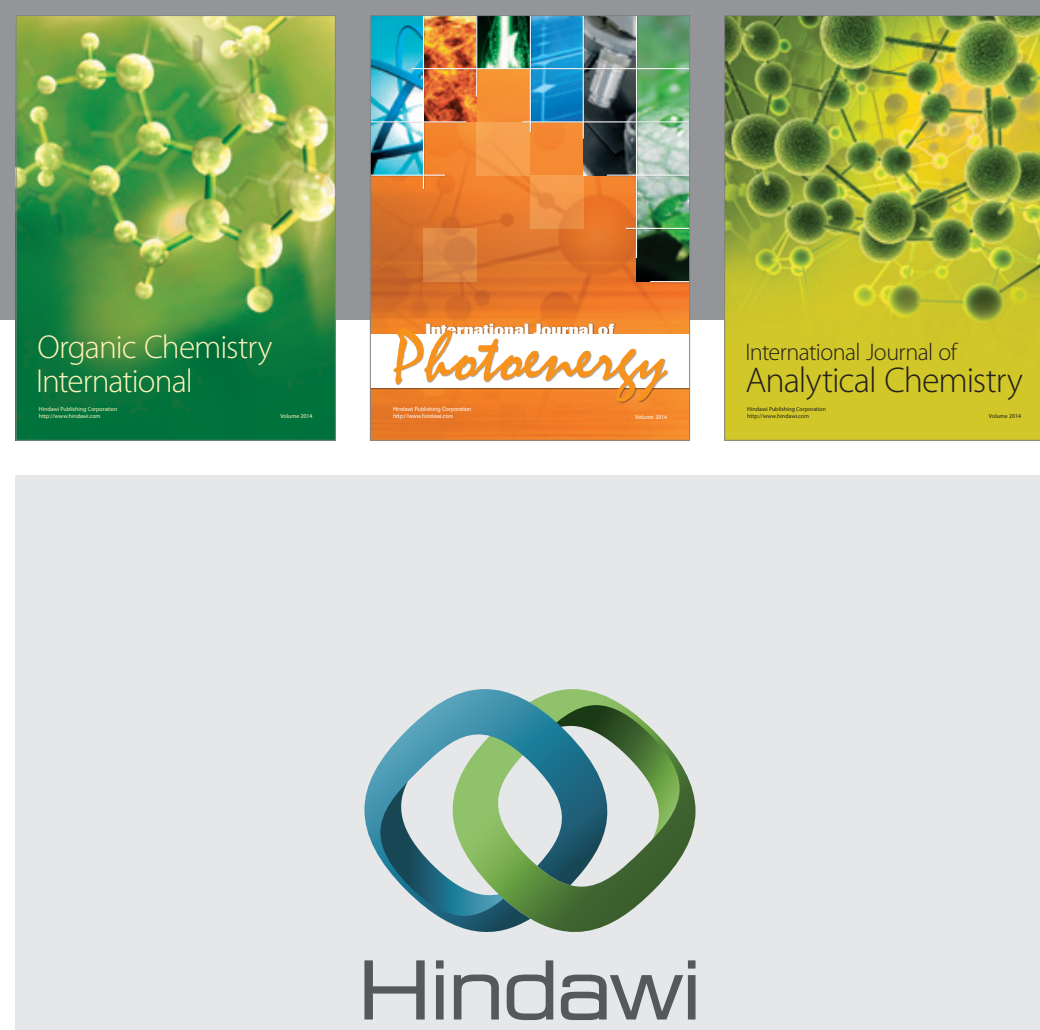

Submit your manuscripts at

http://www.hindawi.com
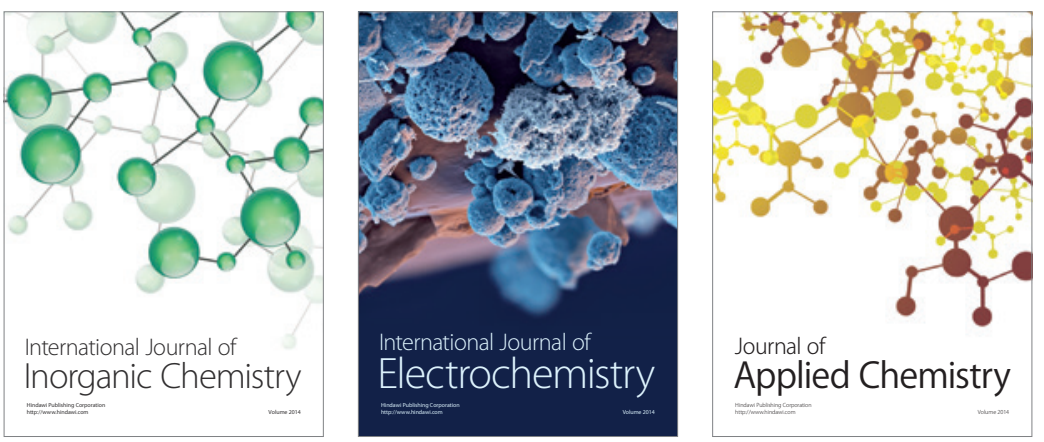

Journal of

Applied Chemistry
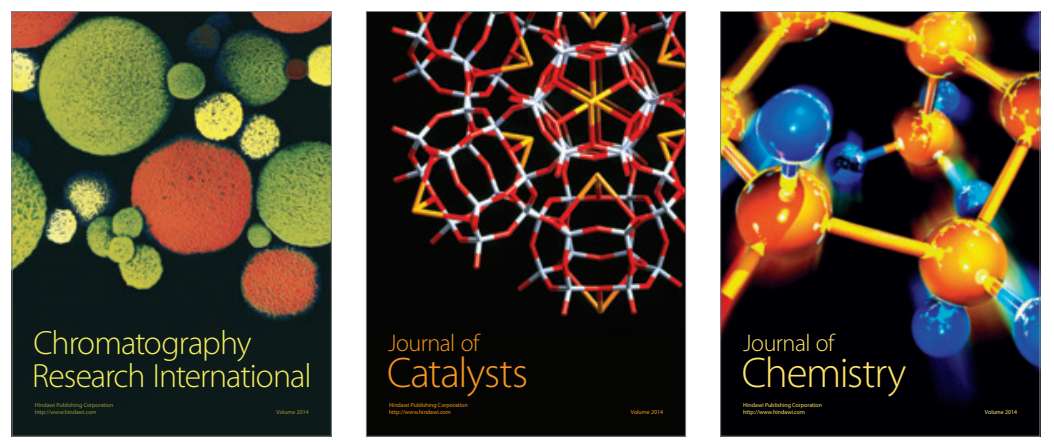
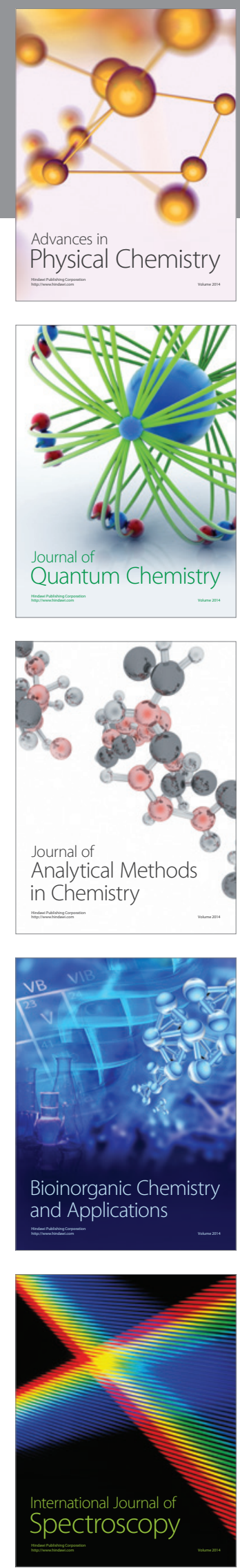